\title{
Application of CRISPR/Cas9 to human- induced pluripotent stem cells: from gene editing to drug discovery
}

\author{
Claudia De Masi, Paola Spitalieri, Michela Murdocca, Giuseppe Novelli and Federica Sangiuolo* (1)
}

\begin{abstract}
Human-induced pluripotent stem cells (hiPSCs) and CRISPR/Cas9 gene editing system represent two instruments of basic and translational research, which both allow to acquire deep insight about the molecular bases of many diseases but also to develop pharmacological research.

This review is focused to draw up the latest technique of gene editing applied on hiPSCs, exploiting some of the genetic manipulation directed to the discovery of innovative therapeutic strategies. There are many expediencies provided by the use of hiPSCs, which can represent a disease model clinically relevant and predictive, with a great potential if associated to CRISPR/Cas9 technology, a gene editing tool powered by ease and precision never seen before.

Here, we describe the possible applications of CRISPR/Cas9 to hiPSCs: from drug development to drug screening and from gene therapy to the induction of the immunological response to specific virus infection, such as HIV and SARS-Cov-2.
\end{abstract}

Keywords: Human-induced pluripotent stem cells (hiPSCs), CRISPR/Cas9, Gene editing, Drug discovery, HIV and SARS-Cov-2 infection, Gene therapy

\section{Background}

Advances in medical research have always been characterized by the continuous exploration of resources able to improve and speed up the achievement of experiments designed to uncover the elements shaping a disease, with the final aim to pinpoint prognostic and diagnostic factors and above all, to identify therapeutic targets and drugs. Frequently, these aims can be reached combining crucial findings, which is the case featuring the conjunction of the latest gene editing techniques and the technology capable to induce pluripotency to somatic cells through the reprogramming mechanisms. Since their discovery, induced pluripotent stem cells (iPSCs) have proved to have a great potential, including the option to overcome ethical and

\footnotetext{
* Correspondence: sangiuolo@med.uniroma2.it

Department of Biomedicine and Prevention, University of Rome "Tor Vergata", Rome, Italy
}

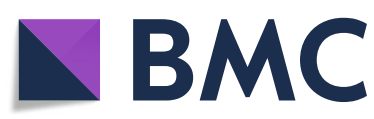

(C) The Author(s). 2020 Open Access This article is licensed under a Creative Commons Attribution 4.0 International License, which permits use, sharing, adaptation, distribution and reproduction in any medium or format, as long as you give appropriate credit to the original author(s) and the source, provide a link to the Creative Commons licence, and indicate if changes were made. The images or other third party material in this article are included in the article's Creative Commons licence, unless indicated otherwise in a credit line to the material. If material is not included in the article's Creative Commons licence and your intended use is not permitted by statutory regulation or exceeds the permitted use, you will need to obtain permission directly from the copyright holder. To view a copy of this licence, visit http://creativecommons.org/licenses/by/4.0/. The Creative Commons Public Domain Dedication waiver (http://creativecommons.org/publicdomain/zero/1.0/) applies to the data made available in this article, unless otherwise stated in a credit line to the data. [1]. To date the chance to access to human cell lines through minimally invasive techniques, such as skin punch biopsy, hair, urine, or blood samples, but also the collection of chorionic villus and amniotic fluid samples, makes obtaining human iPSCs (hiPSCs) more feasible [2-5]. Therefore, today, these cells are used for extensive studies employing both donor-derived healthy and diseased cell lines. In fact, hiPSCs can exhibit phenotypes close to human pathology, so they can represent a disease model clinically relevant and, in some cases, more predictive than the currently available animal-derived or tumor cell-derived cells [6]. hiPSCs are able to reflect patient physiology, pathophysiology, and pharmacological responsiveness, imitating human organs and their microenvironment, particularly when cultured under conditions recapitulating tissue architecture in multicellular spheroids or organoids [7]. 
Taken together these features, in concomitance with the recent evidences about hiPSCs paracrine effects [8], make these cells the ideal candidate to promote endogenous regenerative repair or to replace injured tissues after cellular transplantation, maintaining patient's genetic background and limiting immune rejections, with the intent to treat diseases in a more personalized manner $[8,9]$.

Recently, the application of hiPSCs has been frequently associated with the use of gene editing, targeting the disease-causing gene in order to study the pathophysiology even more deeply, carry out drug screening, and improve cell therapeutic potential [10].

Actually, the most powerful gene editing tool is embodied by clustered, regularly interspaced, short palindromic repeats (CRISPR) and CRISPR-associated protein (CRISPR/Cas9). This can be considered one of the most powerful and versatile technology both for gene editing and transcriptional control but also for epigenetic modulation. Its assembling with hiPSCs is having important implications for scientific research [11].

The aim of this review is to summarize the pivotal roles of hiPSCs in medical and pharmacological research in concomitance with the employment of CRISPR/Cas9 system, focusing the attention on their expediencies for the investigation of new drugs and therapeutic alternatives (Fig. 1).

\section{hiPSCs as a drug discovery device}

Just after the spread of the reprogramming technology, getting a disease model through the employment of
hiPSCs has been used to test several candidate drugs for different pathologies. This expedites the process leading to the clinical application of a particular compound, especially if it has been previously approved for the treatment of other diseases, improving the identification of possible targets and drugs, but also optimizing the selection and stratification of trial participants [11]. However, hiPSCs constitute a successful method when they have to reproduce monogenic diseases, while they may still have limitations in cases of sporadic disorders, where the environmental factors could contribute to the onset of a de novo mutation $[9,12]$. Another challenge is embodied by the reproduction of late-onset disorders, since differentiated cells from hiPSCs have fetallike properties, so it is necessary the induction of cellular aging $[13,14]$. In addition, the epigenetics status of hiPSCs individual clones could be influenced by factors of culture conditions during the reprogramming process [12].

The chance to get hiPSCs isogenic cell line ensures to establish a genetically defined condition, overcoming the genetic background variations between patient and controls hiPSCs, as well as any other variables due to age or sex. In this way, a full range of controls is available to support (wild type (WT)-hiPSCs, patient-hiPSCs, and corrected-patient-hiPSCs) the validation of drug screening results $[9,10]$.

The first hiPSCs large-scale drug screening was performed in 2009, when patient-specific hiPSCs were

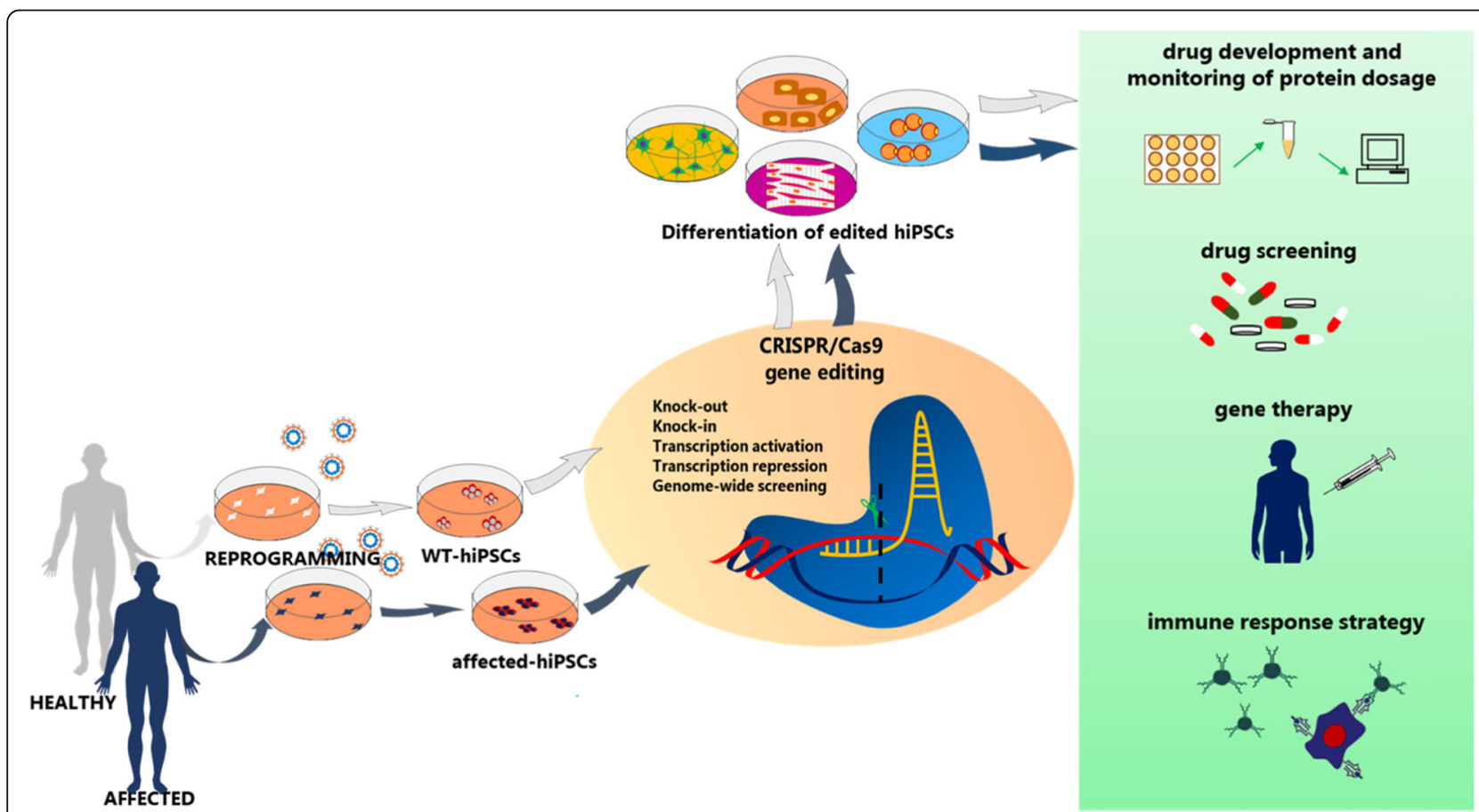

Fig. 1 Workflow of the research involving hiPSCs and CRISPR/Cas9 gene editing for the investigation of new drugs and therapeutic alternatives 
employed to model familial dysautonomia (FD, OMIM \#223900), a peripheral neuropathy coupled with the degeneration of the autonomic and sensory neurons, caused by a point mutation in IkB kinase complexassociated protein (IKBKAP8), resulting in tissue specific splicing defect. Lee and colleagues [15] found three important parameters of FD through hiPSCs disease model. Then, they tested some candidate drugs that could have had an impact on the features found, coming to discover that the kinetin plant hormone could mitigate the pathological phenotype [15].

This cellular approach has led to the evaluation of several compounds for severe diseases, and from then, many drug screening tests have been conducted on hiPSCs, both for testing the efficacy and the toxicity of different compounds.

Some of the latest hiPSCs drug screenings are summarize in Table 1.

Very recently, a trial has been started with the aim of testing the clinical efficacy of Bosutinib, a Src/c-Abl inhibitor [26], identified as a candidate molecular target therapy for amyotrophic lateral sclerosis (ALS, OMIM
\#105400). Src and Abl are tyrosine kinase associated with proliferation, apoptosis. and angiogenesis; they are considered a target of cancer therapy [23]. Different studies have demonstrated that some brain-penetrant tyrosine kinase inhibitors can attenuate the phenotype of neurodegenerative diseases associated with protein aggregation $[27,28]$. Before developing the clinical trial, a drug phenotypic screening of existing Src/c-Abl inhibitors was performed using motor neurons generated from ALS patient-derived hiPSCs [23]. This advanced study resulted in a hiPSCs-based drug repurposing, as Bosutinib had already been approved by Food and Drug Administration (FDA) for the treatment of chronic myelogenous leukemia (CML, OMIM \#608232) [26]. To date the mentioned trial is going to evaluate the efficacy, safety, and tolerability of Bosutinib in combination with the physical conditions of ALS patients, especially since this drug may cause some adverse effects [26, 29].

Actually, many efforts are being made to cut down the costs of drug development and to speed up this process, searching for novel tools that allow to predict drugs side effects, but also to test new drugs ensuring reliability

Table 1 Latest hiPSCs drug screening

\begin{tabular}{|c|c|c|c|c|}
\hline Research field & hiPSCs-derived cells & Drugs tested & Outcome & Ref \\
\hline Colon cancer & $\begin{array}{l}\text { Cardiomyocytes and endothelial } \\
\text { cells, cocultured with tumor } \\
\text { spheroids }\end{array}$ & $\begin{array}{l}2 \text { anticancer drugs were tested } \\
\text { in order to simultaneously } \\
\text { assess cardiac toxicity and } \\
\text { antitumor effects }\end{array}$ & $\begin{array}{l}\text { Demonstration of the feasibility } \\
\text { to simultaneously assess cardiac } \\
\text { toxicity and antitumor drugs } \\
\text { effects }\end{array}$ & [16] \\
\hline $\begin{array}{l}\text { Lesch-Nyhan disease } \\
\text { (OMIM \#300322) }\end{array}$ & Cortical neurons & Test of 3838 compounds & $\begin{array}{l}\text { Identification of } 6 \text { pharmacological } \\
\text { compounds correcting } \\
\text { phosphoribosyltransferase (HGPRT) } \\
\text { deficiency-associated neuronal } \\
\text { phenotypes }\end{array}$ & [17] \\
\hline Progressive fibrosis & Mesenchymal-like cells & $\begin{array}{l}\text { Libraries of } 17000 \text { small } \\
\text { molecules }\end{array}$ & $\begin{array}{l}\text { Identification of anti-fibrotic small } \\
\text { molecule }\end{array}$ & [18] \\
\hline $\begin{array}{l}\text { Neuroprotective activity of } \\
\text { pharmacological compounds }\end{array}$ & $\begin{array}{l}\text { Embryoid bodies, neuronal } \\
\text { precursors and neurons }\end{array}$ & $\begin{array}{l}\text { Screening of peptides of the } \\
\text { melanocortin family and } \\
\text { endocannabinoids for } \\
\text { cytotoxicity, embryotoxicity, } \\
\text { and neuroprotective potential }\end{array}$ & $\begin{array}{l}\text { Both melanocortin peptides and } \\
\text { endocannabinoids exerted } \\
\text { neuroprotective effects }\end{array}$ & [19] \\
\hline $\begin{array}{l}\text { Pro-regenerative drug } \\
\text { development }\end{array}$ & Cardiomyocytes & $\begin{array}{l}\text { Test of } 150 \text { small molecules } \\
\text { with pro-regenerative potential }\end{array}$ & $\begin{array}{l}\text { Identification of } 2 \text { pro-proliferative } \\
\text { compounds acting via the } \\
\text { mevalonate pathway. }\end{array}$ & [20] \\
\hline $\begin{array}{l}\text { Alzheimer's disease } \\
\text { (OMIM \#104300) }\end{array}$ & Neurons & Test of R33 molecule & R33 is able to reduce $A \beta$ and pTAU & [21] \\
\hline Schizophrenia (SZ) & Neural progenitor cells & $\begin{array}{l}\text { Screening of } 135 \text { drugs with } \\
\text { predicted or known interactions } \\
\text { in SZ-biology }\end{array}$ & $\begin{array}{l}\text { Identification of } 52 \text { drugs ameliorating } \\
\text { the SZ-related transcriptomic signature } \\
\text { hiPSCs-derived neural progenitor cells }\end{array}$ & [22] \\
\hline $\begin{array}{l}\text { Amyotrophic lateral sclerosys } \\
\text { (ALS) (OMIM \#105400) }\end{array}$ & Motor neurons & $\begin{array}{l}1416 \text { compounds involved in } \\
\text { motor neurons survival }\end{array}$ & $\begin{array}{l}\text { Identification of Src/c-Abl inhibitors } \\
\text { increasing the survival rate of ALS } \\
\text { motor neurons }\end{array}$ & [23] \\
\hline $\begin{array}{l}\text { Homozygous familial } \\
\text { hypercholesterolemia } \\
\text { (OMIM \#144010) }\end{array}$ & Hepatocytes & $\begin{array}{l}\text { Screening of a library of } 2320 \\
\text { existing drugs }\end{array}$ & $\begin{array}{l}\text { Identification of } 5 \text { cardiac glycosides } \\
\text { able to reduce the hepatocytes } \\
\text { production of apoB }\end{array}$ & [24] \\
\hline Long-QT syndrome & Cardiomyocytes & $\begin{array}{l}\text { Test of LUF7346, known hERG } \\
\text { allosteric modulators }\end{array}$ & $\begin{array}{l}\text { LUF7346 is able to rescue some } \\
\text { phenotypic features of Long-QT- } \\
\text { syndrome }\end{array}$ & [25] \\
\hline
\end{tabular}


and reproducibility in the outcome of drug treatment [30]. The ideal device should be provided with all of these features, without neglecting the genetic and epigenetic variations, but also the environmental factors and other situations that can potentially promote an increase in complexity level of pharmaceutical testing, such as the possible drug-drug interaction [6].

To meet these needs, the attention is now focused on the Organ-On-a-Chip (OOC) technology. This is a twodimensional or three-dimensional microfluidic device of engineered biomaterials with an extracellular matrix amenable for the reproduction and observation of human cells behavior, from the adhesion to migration and from replication to differentiation [6]. The OOC consists of an array of microfluidic channels, which recurrently perfuse biological fluids that contain nutrients, biological factors and drugs, in a controllable manner [6]. In addition, it could be combined with an automated microdevice-monitoring component, which permits repeated measurements of the physiological parameters for the evaluation of drugs effects and toxicity. The OOC could be engineered using hiPSCs, offering the chance to build a personalized drug-testing platform, providing an effective uptake of the human pathophysiology, specifically designed for each patient [6]. Anyway, the OOC technology is characterized by some limitations including the technical challenges of the fabrication of the device but also the cost and inadequacy of acquired human materials. Furthermore, the device should provide a functional organ replication, so it is important to achieve an adequate growth and differentiation of the human tissues. This could represent a risk, because the use of particular growth factors and differentiation reagents, required for a particular cell type, could adversely affect other cells [6].

One of the strengths of the hiPSCs is based on their use not only for target-based screening but also for phenotypic screening. In the last few years, the phenotypic screenings are undergoing a reassessment to which hiPSCs have contributed, above all because they provide an easy access to multiple cell types disease-involved, especially those hard to obtain [31, 32]. For example, phenotypic screening for pain research has always been hampered by the lack of recruit enough neuronal cell types [33]. Now sensory neurons can be derived from hiPSCs, and they can be recruited to develop functional assay of neuronal excitability to be then employed for the evaluation of the phenotypic effects of a smalltargeted validation compound subset [33]. Lately, hiPSCs have set the foundation for the development of a 3D human stem cell platform to screen cortical organoids with high-throughput screening (HTS) [34]. By assembling the reprogramming technology with the use of high content imaging, it was possible to obtain Serum-Free
Embryoid Bodies (SFEBs) and then to determine neurite outgrowth and cellular composition. In this way, the detection of neurite morphology and multi-electrode array analysis were carried out [34]. This approach turned out to be a valid idea for countering the experimental variability common in 3D cultures; this study makes the conjunction between SFEBs and HTS the baseline for phenotypic drug screening [34].

\section{CRISPR/Cas9 system: the latest tool for gene editing}

Gene editing acts as a tool to modify genome, allowing to correct, write, or remove a genetic information into a specific DNA sequence. Today, the available devices to edit DNA are provided with unprecedented ease and precision [35]. This can be translated into the possibility to repair the putative causative lesions in patient-derived cells or to introduce them in cells derived from healthy individuals, thus identifying the mutations involved in the disease phenotype [36].

From the 1970s to the 1980 s, several methods were studied to alter a specific DNA locus, when genomic changes were carried out in yeast and in mice, using a gene target approach based on the process of the homologous recombination (HR) [37]. Recent advances have increased the efficiency of gene editing, implying the acquirement of the skill to induce a targeted DNA doublestrand break (DSB) in the sequence of interest. Actually, the three main procedures able to induce DSBs are zinc finger nucleases (ZFNs), transcription activator-like effector nucleases (TALENs), and CRISPR/Cas9. They are all platforms defined by high target specificity, ease of use, and efficiency [10,37]. Their activity is led by a nuclease, and their potential has been observed in natural biological processes [37].

ZFNs consist essentially of a set of a zinc finger DNAbinding domain, originally identified in sequencespecific eukaryotic transcription factors, fused with a DNA-cleavage domain from a bacterial protein [37]. They are designed to recognize 3-6 nucleotide triplets, with the frequent engagement of two or more zinc fingers [10, 38]. ZFNs-derived genomic modification is based on three main steps: the bond to the target sequence, the cleavage, and the genomic modification resulted from the activation of endogenous DNA repair [37]. These are the same passages exploited by TALENs, which are restriction enzymes secreted by plant pathogenic bacteria when they promote infection [10,37]. A DNA-binding domain and a DNA-cleavage domain able to introduce DSBs into the DNA target sequence characterize TALENs technologies. The mechanism of action is based on a simple one-to-one code of recognition between modules in the protein and base pairs in the DNA target [10]. 
TALENs and ZFNs are broadly used both for disease modelling and therapeutic purposes, but their accuracy and specificity are less than those of CRISPR/Cas9. Moreover, there are still difficulties to face about the protein design, synthesis, and validation that do not allow their routine use [10,37]. By the way, if a homologous donor DNA is provided, repair can proceed by HR. Otherwise, the break can be repaired by non homologous end joining (NHEJ) with the possibilities to introduce occasional errors, like small insertions and deletions (indels) [37, 39].

The CRISPR/Cas9 system was born to be a system of the adaptive immunity to viruses and plasmids in $\mathrm{Bac}$ teria and Archaea. It is known that three CRISPR/Cas9 types exist [40]. Among them, type II is the best known and finds application in genome engineering, because it requires only a single protein for RNA-guided DNA recognition and cleavage. Type II is a two-component RNA-programmable system, based on an endonuclease Cas9 that uses RNA guide sequences to form base pairs with DNA target sequences [40]. This recognition enables Cas9 to introduce a site-specific double-strand break in the DNA. The RNA-guide sequence is an RNAduplex of tracrRNA (transactivating crRNA) and crRNA (CRISPR RNA). They have been engineered as a single guide RNA (sgRNA) with two critical features: a sequence at the $5^{\prime}$ side, that determines the DNA target site by base pairing, and a duplex RNA structure at the 3 ' side that binds to Cas9 [40]. This apparatus resulted to be simple because introducing a change in the guide sequence of the sgRNA induces Cas9 to target any DNA sequence of interest $[10,40]$.

The targeted sequence recognition has two key elements: the protospacer sequence, which has to be complementary to the $5^{\prime}$-end 20-nt sequence of crRNA, and the presence of an essential short sequence, named protospacer adjacent motif (PAM) bound by Cas9 [40]. The CRISPR/Cas9 system will be able to cut and to introduce a DSB after these two conditions occur: the protospacer pairs to $5^{\prime}$-end 20-nt sequence and the bound between Cas9 and the PAM sequence [41]. PAM is critical for initial DNA binding, as some studies showed that Cas9 does not recognize target sequences fully complementary to the guide RNA in the absence of PAM [41].

After the system has acted, DNA repair machinery works with the aim to fix the induced DSB catalyzing NHEJ or HDR [41]. The mechanism of CRISPR/Cas9mediated genome targeting includes conformational rearrangements, the first upon binding to the guide RNA and the second after the association with a target double-stranded DNA. Indeed, Cas9 architectures define two lobes harboring two nucleic acid clefts and undergoing guide RNA-induced reorientation in order to form a central channel where DNA substrates are bound [42, 43].

Despite that most of these knowledges about CRISPR/ Cas9 have their origin in microbiological studies, in 2013, it was clear that this system could be efficiently applicable to edit the genome of human cells [40]. In the last few years, RNA-programmable S. Pyogenes Cas9mediated gene editing has been applied to various human cells, including embryonic stem cells [44, 45], with different goals: the precise reproduction of tumorassociated translocations, the analysis of gene functions through loss-of-function genetic screening, and above all the correction of genetic mutations responsible for inherited disorders [46-49].

In light of the operating mechanism, it is possible to assume that CRISPR/Cas9 is the most easy-to-use and cost-effective technology, because it requires only a change in the guide RNA sequence to modify the target site [40]. Finally, to make the best use of this gene editing system, it is necessary to design the right sgRNA, choosing the most suitable sgRNA design tools, and to find out potential off-target sites, improving sgRNA specificity [37]. The off-target predominantly occurs at sites bearing a PAM and partially complementary to the guide RNA sequence [37]. However, over the years, many efforts have been focused on the enhancement on the system to reduce off-targets $[50,51]$. These efforts have been focused to develop a nickase version of Cas9 (D10A mutant) directed by paired guide RNAs or an engineered Cas9 nuclease variants with enhanced specificity (eSpCas9). Other advances have been oriented towards the development of a CRISPR/Cas9 capable to execute a genome edit without the need of DSBs [52].

The most recent successful attempt to improve this system derives from the prime editing, a versatile and precise genome editing method that uses a catalytically impaired Cas9 fused to an engineered reverse transcriptase, programmed with a Prime Editing Guide RNA (pegRNA) [53]. The special feature lies in a pegRNA that both specifies the target site and encodes the desired edit, thanks to its extension from which it enables the system to copy the genetic information directly [53]. Anzalone et al. reported the potential of this innovative tool to practice a gene editing without DSBs or donor DNA, performing more than 175 edits in human cells, with the plus side to have much lower off-target activity than Cas9. Prime editing was tested on the mutations responsible for sickle cell disease (OMIM \#603903) and Tay Sachs disease (OMIM \#272800). Moreover, it has been evaluated for the introduction of a protective variant in PRNP gene in HEK cells, the insertion of a transversion in DNMT1 gene in mouse primary cortical neurons, and also for a comparison between prime editing and HDR in four human cell lines (HEK293T, K562, 
U2OS, and HeLa). The results highlight the good efficiency of the prime editing and its ability to expand the purposes of the genome editing, correcting a high percentage of known genetic variants associated with human disorders, with a lower degree of off-target and fewer byproducts than HDR [53].

\section{Overview of CRISPR/Cas9 gene editing in hiPSCs}

Reprogramming of somatic cells and genome editing represents two technologies capable to change radically biological and medical research in recent years, reinforcing the role of stem cells in translational medicine. After the design of the correct sgRNA, CRISPR/Cas9 can target a wide number of genomic sequences, through gene knockout or knock-in, gene interference or activation, and other chromosome-related applications, maintaining unchanged the remaining part of the genetic background [54].

Starting from the basic biological studies on hiPSCs, CRISPR/Cas9 system has been used in different ways depending on the purpose of the research as follows:

- Gene knockout is mainly applied to study gene function, because it is the most used implement to establish a connection between a biological event and the upstream molecular mechanism [55].

- Gene knock-in, with the introduction of an exogenous nucleotide sequence, is typically responsible of the identification of specific markers in stem cells research [56].

- Transcription activation or repression: some Cas9 variants (e.g., dCas9, dead Cas9) are deprived of their endonucleolytic activity but maintaining unaltered the ability to generate the gRNA/Cas9 complex. These variants could be fused with transcriptional activator or suppressor, in order to modulate the transcription of endogenous genes [57].

- Genome-wide screening: gRNA libraries provide a large volume of genes for analyzing results through sequencing data collection. While RNA interference (RNAi) libraries knock down gene expression at mRNA level, CRISPR/Cas9 is able to target gene knock-out or transcription inhibitors [58].

These mutations could be evaluated both for basic biological studies on stem cells but also in medical research for disease modelling and drug screening [58].

The first attempts to genetically modify hiPSCs were characterized by the need of an insertion of a floxed resistance cassette. LoxP cassette is usually introduced by homologous recombination with the antibiotic gene, but its removal could induce the presence of residual LoxP sequences that may induce uncontrolled phenotypes [59].
Even before the setup of a mechanism affording the isolation of single-base genome-edited hiPSCs without antibiotic selection [60], CRISPR/Cas9 had been used to obtain isogenic cell lines for disease modelling and cell therapy. One of the first study focused on this direction was finalized to design a specific gRNA for the correction of a point mutation in $H B B$ locus, responsible for sickle cell disease (OMIM \#603903) [61]. The compound was designed with the gRNA, the Cas9 associated with a donor DNA template containing the WT HBB DNA, and a selection cassette subsequently removed. The authors differentiated both the corrected and parental hiPSCs into erythrocytes, demonstrating the production of HBB protein from the corrected allele in the erythrocytes derived from gene-edited hiPSCs [61]. The importance of the availability of an isogenic cells line is closely related to the chance to find out the role of a particular gene and thus the consequences of its possible mutation, as described in a recent study [62]. In this paper is reported the correction of ATM mutations in Ataxia-Telangiectasia (OMIM \#208900) patient-derived hiPSCs through the application of CRISPR/Cas9 approach [62]. Gene corrected hiPSCs showed the improvements reached after gene editing: the restoration of DNA damage and oxidative stress response [62]. Along with the generation of isogenic cell lines, CRISPR/Cas9 technology could be also applied to WThiPSCs in order to generate the specific mutation responsible for the investigated pathology. One example has been published very recently to model the autosomic dominant polycystic kidney disease (ADPKD, OMIM \#613095) [63]. The study started from hiPSCs derived from healthy individuals where the CRISPR/Cas9-mediated knocked out of the PKD2 gene was performed [63]. The same approach has been followed for the introduction of a patient specific point mutation in MEN1 gene into WT cell line, including a donor oligonucleotide carrying the mutation [64]. Here, the association between the gene editing and the hiPSCs helped to explain the molecular differences in hypoglycemic phenotype showed in two patients carrying the same mutation [64].

\section{Application of CRISPR/Cas9 to hiPSCs for the discovery of new therapeutic strategies}

Given the potential of the multiple applications of CRISPR/Cas9 to hiPSCs, their combination can be considered an opportunity for the development of novel therapeutic strategies.

The main ways to get CRISPR/Cas9 and hiPSCs closer to pharmaceutical research are treated below and summarized in Table 2.

\section{Drug development}

Through genetic manipulation applied to hiPSCs, it is possible to introduce particular genetic changes in the 
Table 2 Summary of the applications of CRISPR/Cas9 on hiPSCs for the identifications of therapeutic strategies

\begin{tabular}{|c|c|c|c|c|c|}
\hline & Research field & hiPSCs-derived cells & CRISPR/Cas9 gene editing & Outcome & Ref. \\
\hline \multirow[t]{2}{*}{ Drug development } & $\begin{array}{l}\text { Evaluation of PEPT1- } \\
\text { mediated intestinal } \\
\text { absorption }\end{array}$ & $\begin{array}{l}\text { Intestinal epithelial- } \\
\text { like cells }\end{array}$ & $\begin{array}{l}\text { Peptide transporter } 1 \\
\text { (PEPT1)-knock-out iPSCs }\end{array}$ & $\begin{array}{l}\text { Setting the basis for the } \\
\text { development of peptide } \\
\text { and peptide-mimetic drugs } \\
\text { as possible substrates of PEPT1 }\end{array}$ & [65] \\
\hline & $\begin{array}{l}\text { Multiple-system atrophy } \\
\text { (OMIM \#146500) }\end{array}$ & Neurons & $\begin{array}{l}\text { Correction of } \mathrm{COQ} 2 \\
\text { mutation }\end{array}$ & $\begin{array}{l}\text { Identification of Q10 as } \\
\text { possible therapeutic target }\end{array}$ & {$[66]$} \\
\hline $\begin{array}{l}\text { Monitoring of protein } \\
\text { dosage }\end{array}$ & FOXG1 syndrome & Interneurons & $\begin{array}{l}\text { Tag FOXG1 gene with } \\
\text { small molecule-assisted } \\
\text { shut-off (sMASh) }\end{array}$ & $\begin{array}{l}\text { Demonstration of FOXG1 } \\
\text { dose-control }\end{array}$ & {$[67]$} \\
\hline \multirow[t]{3}{*}{ Gene therapy } & $\begin{array}{l}\text { Beta-thalassemia } \\
\text { (OMIM \#613985) }\end{array}$ & $\begin{array}{l}\text { Hematopoietic stem } \\
\text { cells }\end{array}$ & $\begin{array}{l}\text { Correction of } H B B \\
\text { mutation }\end{array}$ & $\begin{array}{l}\text { Corrected-hematopoietic } \\
\text { stem cells transplantation } \\
\text { as therapeutic strategy }\end{array}$ & $\begin{array}{l}{[68,} \\
69]\end{array}$ \\
\hline & $\begin{array}{l}\text { Recessive dystrophic } \\
\text { epidermolysis bullosa } \\
\text { (OMIM \#226600) }\end{array}$ & $\begin{array}{l}\text { Keratinocytes and } \\
\text { fibroblasts }\end{array}$ & $\begin{array}{l}\text { Correction of COL7A1 } \\
\text { mutation }\end{array}$ & $\begin{array}{l}\text { Restoration of the regular } \\
\text { collagen type VII expression }\end{array}$ & [70] \\
\hline & $\begin{array}{l}\text { Duchenne } \\
\text { muscular dystrophy } \\
\text { (OMIM \#310200) }\end{array}$ & Skeletal muscle cells & DMD exon 44 knock-in & $\begin{array}{l}\text { Restoration of full protein } \\
\text { coding-region }\end{array}$ & [71] \\
\hline \multirow[t]{2}{*}{ Drug screening } & $\begin{array}{l}\text { mtDNA } \\
\text { depletion syndrome } \\
\text { (OMIM \#251880) }\end{array}$ & Hepatocytes & $\begin{array}{l}\text { Inducing DGUOK } \\
\text { knock-out }\end{array}$ & $\begin{array}{l}\text { Identification of compound } \\
\text { able to restore mithocondrial } \\
\text { function }\end{array}$ & {$[72]$} \\
\hline & $\begin{array}{l}\text { Alzheimer's disease } \\
\text { (OMIM \#104300) }\end{array}$ & Neurons & $\begin{array}{l}\text { Correction of PSEN1 } \\
\text { G384A mutation }\end{array}$ & $\begin{array}{l}\text { Identification of a synergistic } \\
\text { combination of bromocriptine, } \\
\text { cromolyn and topiramate as } \\
\text { an anti-A } \beta \text { cocktail }\end{array}$ & [73] \\
\hline \multirow[t]{4}{*}{$\begin{array}{l}\text { Immune response } \\
\text { strategy }\end{array}$} & HIV infection & Macrophages & $\begin{array}{l}\text { Introduction of 32bp- } \\
\text { depletion in CCR5 gene }\end{array}$ & $\begin{array}{l}\text { Generation of immune cells } \\
\text { resistant to HIV-infection }\end{array}$ & [74] \\
\hline & HIV infection & $\begin{array}{l}\text { Monocytes/ } \\
\text { macrophages }\end{array}$ & $\begin{array}{l}\text { Engineer hiPSCs to express a } \\
\text { CRISPR/Cas9 system directed } \\
\text { against the reverse-transcribed } \\
\text { products of the viral RNA } \\
\text { genome }\end{array}$ & $\begin{array}{l}\text { Stable expression of HIV- } \\
\text { targeted CRISPR/Cas9 in } \\
\text { hiPSCs-derived reservoir cells }\end{array}$ & {$[75]$} \\
\hline & SARS-Cov-2 infection & Pneumocytes type II & $\begin{array}{l}\text { Regulation of genes } \\
\text { involved in viral infection }\end{array}$ & $\begin{array}{l}\text { Building a cell platform to } \\
\text { test the capacity of candidate } \\
\text { antiviral compounds }\end{array}$ & [76] \\
\hline & Solid tumors & Natural killer & $\begin{array}{l}\text { hiPSCs were edited with } \\
\text { CRISPR/Cas9 to repress } \\
\text { ADAM17 expression }\end{array}$ & $\begin{array}{l}\text { Obtaining natural killer cells } \\
\text { directed against tumor cells }\end{array}$ & {$[77]$} \\
\hline
\end{tabular}

early phase of drug discovery process that could be useful for the development of a particular compound or to choose the perfect drug candidate. Recently, Kawai et al. [65] have published their experiments about the use of CRISPR/Cas9 to induce peptide transporter 1 (PEPT1)knock-out hiPSCs, differentiating them into intestinal epithelial-like cells (IECs). The aim of this study was to evaluate the PEPT1-mediated intestinal absorption, in order to set the basis for the development of peptide and peptide-mimetic drugs as possible substrates of PEPT1 [65]. Thus, the use of hiPSCs found its emplacement into pharmacokinetic testing. They demonstrated that PEPT1 expression levels in hiPSCs-IECs were similar to those in human adult small intestine and that these cells exhibited PEPT1 activity. For the first time, CRISPR/Cas9 was used to deplete a particular glutamate present in exon 21, required for PEPT1 transport ability.
The result was the constitution of a PEPT1-KO-hiPSCsIECs line, which can be employed in highly specific transporter assay for the evaluation of PEPT1 substrates, without the use of inhibitors [65].

Another step of drug development is the identification of specific therapeutic targets involving the use of hiPSCs and CRISPR/Cas9 gene editing. Their assembling was implemented in the research about a particular neurodegenerative disease named multiple-system atrophy (MSA, OMIM \#146500) [66]. MSA is characterized by autonomic failure with different classifications based on the involvement of parkinsonism, cerebellar ataxia, and pyramidal dysfunction. Nakamoto et al. [66], with the aid of hiPSCs-patient-derived neurons, studied a form of MSA related to a functionally impaired variant of $C O Q 2$ gene, associated with a reduction in Q10 biosyntesis. By using the gene correction mediated by CRISPR/Cas9, it 
was possible to reverse the resulting functional deficiencies in mitochondrial respiration and antioxidative system as well as the increased apoptosis. Hence, this study relates neuron dysfunctions with the decreased coenzyme Q10, thus assuming that a supplementation of Q10 could represent a useful option for MSA therapy [66].

\section{Monitoring of protein dosage}

Monitoring the amount of particular proteins is one of the main purposes in the investigations of disorders characterized by the accumulation of some products. After all, there are genetic alterations inducing half-loss, functional impairment, and de novo gain of function which are responsible for abnormal protein dosage [78, 79]. One example is the unusual storage of key regulators in developmental disorders, as in FOXG1 syndrome (OMIM \#613454). Forkhead transcription factor1 (FOXG1) is variably expressed at early stage of brain development [80]. It has been already demonstrated that human deletions or missense mutations on one allele of FOXG1 cause severe neurodevelopmental disorders named FOXG1 syndrome, with many phenotypic manifestations including autism spectrum disorder, epilepsy, microcephaly, and severe intellectual disability [81-83]. Zhu et al. [67] for the first time tried to control FOXG1 dosage by combining three technologies: CRISPR/Cas9, small molecule-assisted shut-off (SMASh), and hiPSCs. This novel combination allows to better manage the difficulties in dosage control usually met when traditional knock-out or knock-down strategies are used. Upon the administration of small molecules (protease inhibitors), SMASh technology is able to alter the post-translational amount of proteins in a precise and reversible manner, thanks to the presence of self-removing degrons [67]. With CRISPR/Cas9, the authors tagged the targeted gene with a SMASh in hPSCs-derived interneurons. Through this architecture, they have been skilled to monitor how FOXG1 dosage affects the generation of GABAergic interneurons, which might explain the variable clinical manifestations of FOXG1 syndrome. The authors tuned this method in order to reproduce a disease model, because controlling protein dosage by druginduced degradation or stabilization makes it easy to study protein function [67]. However, this could find interesting applications in pharmaceutical purposes screening drugs with the aim to restore the normal protein quantity, in order to decrease or remove the severe clinical manifestations of syndromes due to alterations in protein amount.

\section{Gene therapy}

One of the main applications derived by the fusion of hiPSCs with CRISPR/Cas9 is gene editing for cell therapy. In fact, hiPSCs allow to take patient cells where genome edit is practicable, and then it is feasible to use them for autologous cell transplant. In 2015, it was demonstrated that the $H B B$ gene correction with CRISPR/ Cas9 of beta-thalassemia (OMIM \#613985) patientspecific hiPSCs, and their derived hematopoietic stem cells transplantation, offers an ideal therapeutic solution for treating the disease $[68,69]$.

Progress have been also done in studying the recessive dystrophic epidermolysis bullosa (RDEB, OMIM \#226600), a severe inherited skin disorder caused by mutations in COL7A1 gene [84]. Jackòw et al. [70] used hiPSCs derived from RDBE patients and corrected them with CRISPR/ Cas9. Three-dimensional skin equivalents (HSEs) were generated from gene-corrected hiPSCs, differentiated into keratinocytes and fibroblasts, and then grafted into immunodeficient mice [70]. Animals showed normal expression of type VII collagen. Therefore, this laid the foundation for future clinical applications of innovative autologous stem cell-based therapies for RDBE [70].

Another study has been focused on the correction of the Duchenne muscular dystrophy (DMD)-causing mutation with TALENs and CRISPR/Cas9 in patientderived hiPSCs [71]. DMD (OMIM \#310200) is a severe muscular degenerative disease caused by loss of function mutations in the dystrophin gene $(D M D)$ located on chromosome X [71]. Patient myoblasts had been previously used for restoration of the dystrophin protein, but their clonal expansion required the immortalization process mediated by oncogene such as hTERT $[71,85]$. Instead, hiPSCs can be isolated from patients maintaining their pluripotency and self-renewal capacity without any further procedures. In this study [71], the authors tried to perform dystrophin correction using three different methods: disruption of the splicing acceptor to skip exon, introduction of small indels to modulate the protein reading frame, and knock-in of the missing exon 44 to restore the full protein coding-region [71]. The results showed that all of these approaches were beneficial, but only the knock-in approach restored the full-length dystrophin protein [71]. The investigations about the $\mathrm{Du}-$ chenne disease have sustained important progress in order to reduce the probability of off-targets mutagenesis and immunogenicity, generally due to the prolonged expression of the CRISPR/Cas9. Very recently, Gee et al. [86] have developed an extracellular nanovesicle-based ribonucleoprotein delivery system named NanoMEDIC. This is developed on chemical dimerization and viral RNA packaging signal to recruit Cas9 protein and sgRNA into nanovesicles [86]. They have tested this device in different cell types, among others in skeletal muscle cells derived from DMD-hiPSCs. The system reached over 90\% exon skipping efficiencies. This innovative technique, as in vivo experiments have demonstrated, seems to be promising for DMD genome editing therapy [86]. 


\section{Drug screening}

The potential and availability of genome editing and reprogramming equipment place at disposal of researchers a valid instrument for drug screening, especially when there is a lack to access to patient samples. After gene editing, cells can be differentiated into specific cell types, target of disease, and a screening of different compounds can be performed, in order to identify those able to ameliorate the disease phenotype. For example, drug screening resulted to be the best way for the identification of the ideal compound to fight the mtDNA depletion syndrome (MTDPS3, OMIM \#251880) caused by the deficiency of DGUOK, a mitochondrial kinase responsible for the phosphorylation of purine deoxyribonucleosides [87]. The liver is the main organ involved in this disease [72]; thus, authors derived hepatocytes from WT-hiPSCs, after inducing DGUOK knockout through CRISPR/Cas9. These cells recapitulated the mitochondrial dysfunction associated with the livers of MTDPS3 patients and consequently were used as platform to identify drugs that could improve mitochondrial function and ATP production [87]. The authors used the SPECTRUM collection library, which contains about 1300 drugs approved for human use in the USA, Europe, and Japan. ATP levels were used to identify compounds that increase cellular energy production. Among the drug examined, NAD was the one that reproducibly increases ATP levels and the expression of all mitochondrial-encoded electron transport chain genes evaluated in this screening [87]. Hence, a possible treatment with NAD could represent a valid therapeutic option. This is one example of how the conjunction of reprogramming and gene editing can provide a highthroughput test system for screening potential therapeutic preparations with different activity spectra.

\section{Immune response strategy}

As previously described, CRISPR/Cas9 was born as immune response in some bacteria for virus removal. This concept has been applied to HIV research, because the actually available therapeutic strategies are not able to totally eradicate the virus from the body and to date many studies are trying to apply genome editing to fight this infection [74]. Concerning the possible application of hiPSCs in this field of medical research, Liao and coll [75]. tried to induce into hiPSCs an antiviral defense system similar to those of bacteria and archaea. They engineered hiPSCs to express a CRISPR/Cas9 system directed against the reverse-transcribed products of the viral RNA genome. The result was the production of hiPSCs which stably expressed HIV-targeted CRISPR/Cas9. These cells can be differentiated into HIV reservoir cells, maintaining a longterm resistance to the virus. So this can be defined an innovative therapeutic strategy against viral infections [75].
Concerning the possible applications of CRISPR/Cas9 and hiPSCs in antiviral response, this apparatus can find an employment in the more current than ever SARSCov-2 research. The driven idea is the building of a testing platform that mimics a human lung, differentiating WT-hiPSCs into pneumocytes type II [88] and treating them with pseudoviruses able to mimic SARS-Cov-2 infection [89]. Then, gene editing can be employed for the repression or the upregulation of genes involved in virus entrance and activity but also for the introduction of known polymorphisms that could protect or predispose to virus infection [90]. Also, edited cells can also be used to test the capacity of a number of candidate compounds to fight the infections. Very recently, a flexible and efficient approach to target virus RNA through CRISPR/ Cas9 action has been implemented; it can be used specifically for SARS-CoV-2 RNA genome, limiting its ability to reproduce [76]. This represents a great opportunity to fight viruses that have the potential to evolve and develop resistance rapidly [76].

Another medical research field, which required the stimulation of the immune response, is oncology. CRISPR/Cas9 in cancer research is already widely used, because the ability to identify and correct such mutations, but also the discovery of molecular targets, are important aims of cancer treatment [91-93]. However, oncology projects exploiting the combination between CRISPR/Cas9 and hiPSCs are scarce. An interesting research has been published in 2016 [77], when a group of researchers tried to improve NK cell-mediated killing solid tumors, engineering them to express a more stable form of CD16a. This protein has a key function in the elimination of cells opsonized by antibodies through the Antibody-Dependent Cell-mediated Cytotoxicity (ADCC). NK cells activity could be hampered by the expression of ADAM17, a metalloprotease that mediated the proteolytic cleavage of CD16a. Thus, hiPSCs were edited with CRISPR/Cas9 to repress ADAM17 expression and soon after also engineered to produce the cleavageresistant CD16a (S197P). These cells have been differentiated into natural killer ones directed against tumor cells, representing an approach for allogenic cell-based immunotherapies [77].

\section{Conclusions and future challenges}

The reprogramming technology with the resulting possibility to use patient-derived pluripotent stem cells has implemented medical research. This breakthrough has undergone a further advancement after the discovery of CRISPR/Cas9 genome editing system. These two tools have a multitude of roles both in basic biological and translational research, with a particular involvement in pharmacological fields and drug development. 
However, many challenges have to be overcome. In particular, it is necessary to improve reprogramming mechanism efficiency and to set up standard protocols, avoiding incomplete reprogramming and the onset of de novo mutations.

The revolution started by the introduction of such advanced tool for gene editing based on a single protein makes difficult to image a system simpler than CRISPR/ Cas9. Anyway, its enhancement is required in order to reduce off-targets effects of genome editing and to build novel strategies for CRISPR/Cas9 delivery into cells, without using virus carriers, unsuitable for clinical application. It would also be appropriate to facilitate the selection and expansion of hiPSCs-CRISPR/Cas9-corrected clones, which are often laborious and time consuming.

In addition, there is the need to evaluate the safety aspects for human trials, both for the application of CRISPR/Cas9 and hiPSCs. Another perspective is to improve target accuracy, with the help of pluripotent stem cells, which can be easily translated to preclinical and clinical studies, enhancing the clinical trial success rate.

Working on these points could have important implications in drug development process, reducing time and cost-effects.

\section{Abbreviations}

iPSCs: Induced pluripotent stem cells; hiPSCs: Human-induced pluripotent stem cells; CRISPR/Cas9: Clustered, regularly interspaced, short palindromic repeats/CRISPR-associated protein; WT: Wild type; FD: Familial dysautonomia; IKBKAP8: IkB kinase complex-associated protein; ALS: Amyotrophic lateral sclerosis; FDA: Food and Drug Administration; CML: Chronic myelogenous leukemia; OOC: Organ-on-a-chip; HTS: High-throughput screening; SFEBs: Serum-free embryoid bodies; HR: Homologous recombination; DSB: Double-strand break; ZFNs: Zinc finger nucleases; TALENs: Transcription activator-like effector nucleases; NHEJ: Non homologous end joining; gRNA: Guide RNA; sgRNA: Single guide RNA; crRNA: CRISPR RNA; tracrRNA: Transactivating crRNA; PAM: Protospacer adjacent motif; pegRNA: Prime editing guide RNA; RNAi: RNA interference; ADPKD: Autosomic dominant polycystic kidney disease; IECs: Epithelial-like cells; PEPT1: Peptide transporter 1; MSA: Multiple-system atrophy; FOXG1: Forkhead transcription factor1; SMASh: Small molecule-assisted shutoff; RDBE: Recessive dystrophic epidermolysis bullosa; DMD: Duchenne muscular dystrophy; MTDPS3: mtDNA depletion syndrome

\section{Acknowledgements}

Not applicable.

\section{Authors' contributions \\ CDM, MM, PS, GN, and FS contributed to the writing of the paper. All authors read and approved the final manuscript.}

\section{Funding}

Not applicable

\section{Availability of data and materials}

Not applicable

Ethics approval and consent to participate

Not applicable

\section{Consent for publication}

Not applicable

\section{Competing interests}

The authors declare that they have no competing interests.

Received: 7 May 2020 Accepted: 17 June 2020

Published online: 26 June 2020

\section{References}

1. Takahashi K, Yamanaka S. Induction of pluripotent stem cells from mouse embryonic and adult fibroblast cultures by defined factors. Cell. 2006;126(4): 663-76

2. Spitalieri P, Talarico VR, Murdocca M, Novelli G, Sangiuolo F. Human induced pluripotent stem cells for monogenic disease modelling and therapy. World J Stem Cells. 2016:8(4):118-35.

3. Spitalieri P, Talarico RV, Botta A, Murdocca M, D'Apice MR, Orlandi A, et al. Generation of human induced pluripotent stem cells from extraembryonic tissues of fetuses affected by monogenic diseases. Cell Reprogram. 2015; 17(4):275-87.

4. Streckfuss-Bömeke K, Wolf F, Azizian A, Stauske M, Tiburcy M, Wagner S, et al. Comparative study of human-induced pluripotent stem cells derived from bone marrow cells, hair keratinocytes, and skin fibroblasts. Eur Heart J. 2013;34(33):2618-29

5. Si-Tayeb K, Idriss S, Champon B, Caillaud A, Pichelin M, Arnaud L, et al. Urine-sample-derived human induced pluripotent stem cells as a model to study PCSK9-mediated autosomal dominant hypercholesterolemia. Dis Model Mech. 2016;9(1):81-90.

6. Jodat YA, Kang MG, Kiaee K, Kim GJ, Martinez AFH, Rosenkranz A, et al. Human-derived organ-on-a-chip for personalized drug development. Curr Pharm Des. 2018;24(45):5471-86.

7. Eglen RM, Reisine T. Human iPS cell-derived patient tissues and 3D cell culture part 1: target identification and lead optimization. SLAS Technol. 2019;24(1):3-17.

8. Phillip C, Yang MD. Induced pluripotent stem cell (iPSCs)-derived exosomes for precision medicine in heart failure. Circ Res. 2018;122(5):661-3.

9. Shi Y, Inoue H, Wu JC, Yamanaka S. Induced pluripotent stem cell technology: a decade of progress. Nat Rev Drug Discov. 2017;16(2):115-30.

10. Li XF, Zhou YW, Cai PF, Fu WC, Wang JH, Chen JY, et al. CRISPR/Cas9 facilitates genomic editing for large-scale functional studies in pluripotent stem cell culture. Human Genetics. 2019;138:1217-25.

11. Zhang J, Chen L, Zhang J, Wang Y. Drug inducible CRISPR/Cas systems. Comput Struct Biotechnol J. 2019;17:1171-7.

12. Kim EJ, Kang KH, Ju JH. CRISPR-Cas9: a promising tool for gene editing on induced pluripotent stem cells. Korean J Intern Med. 2017;32:42-61.

13. Studer L, Vera E, Cornacchia D. Programming and reprogramming cellular age in the era of induced pluripotency. Cell Stem Cell. 2015;16:591-600.

14. Nguyen HN, Byers B, Cord B, Shcheglovitov A, Byrne J, Gujar P, et al. LRRK2 mutant iPSC-derived DA neurons demonstrate increased susceptibility to oxidative stress. Cell Stem Cell. 2011;8:267-80.

15. Lee G, Papapetrou EP, Kim H, Chambers SM, Tomishima MJ, Fasano CA, et al. Modelling pathogenesis and treatment of familial dysautonomia using patient-specific iPSCs. Nature. 2009;461(7262):402-6.

16. Weng KC, Kurokawa YK, Hajek BS, Paladin JA, Shirure VS, George SC. Human induced pluripotent stem-cardiac-endothelial-tumor-on-a-chip to assess anticancer efficacy and cardiotoxicity. Tissue Eng Part C Methods. 2020;26(1): 44-55.

17. Ruillier V, Tournois J, Boissart C, Lasbareilles M, Mahé G, Chatrousse L, et al. Rescuing compounds for Lesch-Nyhan disease identified using stem cellbased phenotypic screening. JCI Insight. 2020. https://doi.org/10.1172/jci. insight.132094.

18. Vijayaraj P, Minasyan A, Durra A, Karumbayaram S, Mehrabi M, Aros CJ, et al Modeling progressive fibrosis with pluripotent stem cells identifies an antifibrotic small molecule. Cell Rep. 2019;29(11):3488-505.

19. Novosadova EV, Arsenyeva EL, Antonov SA, Vanyushina YN, Malova TV, Komissarov AA, et al. The use of human induced pluripotent stem cells for testing neuroprotective activity of pharmacological compounds. Biochemistry (Mosc). 2019;84(11):1296-305.

20. Mills RJ, Parker BL, Quaife-Ryan GA, Voges HK, Needham EJ, Bornot A, et al. Drug screening in human PSC-cardiac organoids identifies pro-proliferative compounds acting via the mevalonate pathway. Cell Stem Cell. 2019;24(6): 895-907.

21. Young JE, Fong LK, Frankowski H, Petsko GA, Small SA, Lawrence SB, et al. Stabilizing the retromer complex in a human stem cell model of 
Alzheimer's disease reduces TAU phosphorylation independently of amyloid precursor protein. Stem Cell Reports. 2018;10:1046-58.

22. Readhead B, Hartley BJ, Eastwood BJ, Collier DA, Evans D, Farias R, et al. Expression-based drug screening of neural progenitor cells from individuals with schizophrenia. Nature Communications. 2018. https://doi.org/10.1038/ s41467-018-06515-4.

23. Imamura K, Izumi Y, Watanabe A, Tsukita K, Woltjen K, Yamamoto T, et al. The $\mathrm{Src} / \mathrm{c}-\mathrm{Abl}$ pathway is a potential therapeutic target in amyotrophic lateral sclerosis. Sci Transl Med. 2017. https://doi.org/10.1126/scitransImed. aaf3962.

24. Cayo MA, Mallanna SK, Di Furio F, Jing R, Tolliver LB, Bures M, et al. A drug screen using human iPSC-derived hepatocyte-like cells identifies cardiac glycosides as a potential treatment for hypercholesterolemia. Cell Stem Cell. 2017;20(4):478-89.

25. Sala L, Yu Z, Ward-van Oostwaard D, Van Veldhoven JPD, Moretti A, Laugwitz KL, et al. A new hERG allosteric modulator rescues genetic and drug-induced long-QT syndrome phenotypes in cardiomyocytes from isogenic pairs of patient induced pluripotent stem cells. EMBO Mol Med. 2016;8(9):1065-81.

26. Imamura K, Izumi Y, Banno H, Uozumi R, Morita S, Egawa N, et al. Induced pluripotent stem cell-based Drug Repurposing for Amyotrophic lateral sclerosis Medicine (iDReAM) study: protocol for a phase I dose escalation study of bosutinib for amyotrophic lateral sclerosis patients. BMJ Open. 2019. https://doi.org/10.1136/bmjopen-2019-033131.

27. Lonskaya I, Hebron ML, Desforges NM, Franjie A, Moussa CE. Tyrosine kinase inhibition increases functional parkin-Beclin-1 interaction and enhances amyloid clearance and cognitive performance. EMBO Mol. Med. 2013;5: 1247-62.

28. Wenqiang C, Lonskaya I, Hebron ML, Ibrahim Z, Olszewski RT, Neale JH, et al. Parkin-mediated reduction of nuclear and soluble TDP-43 reverses behavioral decline in symptomatic mice. Hum Mol Genet. 2014;23(18):4960-9.

29. Cortes JE, Apperley JF, DeAngelo DJ, Deininger MW, Kota VK, Rousselot P, et al. Management of adverse events associated with bosutinib treatment of chronic-phase chronic myeloid leukemia: expert panel review. J Hematol Oncol. 2018;11(1):143.

30. Anson BD, Kolaja K, Kamp TJ. Opportunities for human iPS cells in predictive toxicology. Clin Pharmacol Ther. 2011;89(5):754-8.

31. Warchal SJ, Unciti-Broceta A. O Carragher N. Next-generation phenotypic screening. Future Med Chem. 2016;8(11):1331-47.

32. Sridharan BP, Hubbs C, Llamosas N, Kilinc M, Singhera FU, Willems E, et al. A simple procedure for creating scalable phenotypic screening assays in human neurons. Sci Rep. 2019. https://doi.org/10.1038/s41598-019-45265-1.

33. Stacey P, Wassermann AM, Kammonen L, Impey E, Wilbrey A, Cawkill D. Plate-based phenotypic screening for pain using human iPSC-derived sensory neurons. SLAS Discovery. 2018;23(6):585-96.

34. Durens M, Nestor J, Williams M, Herold K, Niescier RF, Lunden JW, et al. High-throughput screening of human induced pluripotent stem cell-derived brain organoids. J Neurosci Methods. 2020. https://doi.org/10.1016/j. jneumeth.2020.108627.

35. Scott A. How CRISPR is transforming drug discovery. Nature. 2018. https:// doi.org/10.1038/d41586-018-02477-1.

36. Bassett AR. Editing the genome of hiPSC with CRISPR/Cas9: disease models. Mamm Genome. 2017;28(7):348-64

37. Carroll D. Genome editing: past, present, and future. Yale Journal of Biology And Medicine. 2017;90:653-9.

38. Carroll D. Genome engineering with zinc-finger nucleases. Genetics. 2011; 188:773-82.

39. Talarico RV, Novelli G, Sangiuolo F, Spitalieri P. Human induced pluripotent stem cells-based strategies: new frontiers for personalized medicine. In: Daniele N, Zinno F, editors. Toward the future: the new challenges of the cell therapy and potential of the regenerative medicine; 2017. p. 105-29.

40. Doudna JA, Charpentier $E$. The new frontier of genome engineering with CRISPR-Cas9. Science. 2014. https://doi.org/10.1126/science.1258096.

41. Cui Y, Xu J, Cheng M, Liao X, Peng S. Review of CRISPR/Cas9 sgRNA design tools. Interdiscip Sci. 2018;10(2):455-65.

42. Jinek M, Jiang F, Taylor DW, Sternberg SH, Kaya E, Ma E, et al. Structures of Cas9 endonucleases reveal RNA-mediated conformational activation. Science. 2014. https://doi.org/10.1126/science.1247997.

43. Nishimasu H, Ran FA, Hsu PD, Konermann S, Shehata SI, Dohmae N, et al. Crystal structure of Cas9 in complex with guide RNA and target DNA. Cell. 2014;156(5):935-49.
44. Kearns NA, Genga RMJ, Enuameh MS, Garber M, Wolfe SA, Maehr R. Cas9 effector-mediated regulation of transcription and differentiation in human pluripotent stem cells. Development. 2014;141(1):219-23.

45. Kim S, Kim D, Cho SW, Kim J, Kim JS. Highly efficient RNA-guided genome editing in human cells via delivery of purified Cas 9 ribonucleoproteins. Genome Res. 2014;24(6):1012-9.

46. Choi PS, Meyerson M. Targeted genomic rearrangements using CRISPR/Cas technology. Nat. Commun. 2014. https://doi.org/10.1038/ncomms4728.

47. Torres R, Martin MC, Garcia A, Cigudosa JC, Ramirez JC, Rodriguez-Perales S. Engineering human tumour-associated chromosomal translocations with the RNA-guided CRISPRCas9 system. Nat. Commun. 2014. https://doi.org/10. 1038/ncomms4964.

48. Xue W, Chen S, Yin H, Tammela T, Papagiannakopoulos T, Joshi NS, et al. CRISPR-mediated direct mutation of cancer genes in the mouse liver. Nature. 2014;514:380-4.

49. Maule G, Casini A, Montagna C, Ramalho AS, Boeck KD, Debyser, et al. Allele specific repair of splicing mutations in cystic fibrosis through AsCas12a genome editing. Nature Communications. 2019. https://doi.org/10.1038/ s41467-019-11454-9.

50. Ran FA, Hsu PD, Lin CY, Gootenberg JS, Konermann S, Trevino AE, Scott DA, Inoue A, Matoba S, Zhang Y, Zhang F. Double nicking by RNA-guided CRISPR Cas9 for enhanced genome editing specificity. Cell. 2013:1380-9.

51. Slaymaker IM, Gao L, Zetsche B, Scott DA, Yan WX, Zhang F. Rationally engineered Cas9 nucleases with improved specificity. Science. 2016;351:84-8.

52. Komor AC, Kim YB, Packer MS, Zuris JA, Liu DR. Programmable editing of a target base in genomic DNA without double-stranded DNA cleavage. Nature. 2016;533:420-4.

53. Anzalone AV, Randolph PB, Davis JR, Sousa AA, Koblan LW, Levy JM, et al. Search-and-replace genome editing without double-strand breaks or donor DNA. Nature. 2019. https://doi.org/10.1038/s41586-019-1711-4.

54. Ran FA, Hsu PD, Wright J, Agarwala V, Scott DA, Zhang F. Genome engineering using crispr-cas9 system. Nat protoc. 2013;8(11):2281-308.

55. McCloskey AG, Miskelly MG, Moore CBT, Nesbit MA, Christie KA, Owolabi Al, et al. CRISPR/Cas9 gene editing demonstrates metabolic importance of GPR55 in the modulation of GIP release and pancreatic beta cell function. Peptides. 2020. https://doi.org/10.1016/j.peptides.2019.170251.

56. Adkar SS, Willard VP, Brunger JM, Shiao KT, Gersbach CA, Guilak F. Targeted genome editing of human induced pluripotent stem cells using CRISPR/ CAS9 to generate a knock-in type II collagen reporter for the purification of chondrogenic cells. Mol. Ther. 2016. https://doi.org/10.1016/S15250016(16)33127-6.

57. Dominguez AA, Lim WA, Qi LS. Beyond editing: repurposing CRISPR-Cas9 for precision genome regulation and interrogation. Nat Rev Mol Cell Biol. 2016 Jan;17(1):5-15.

58. Zhang Z, Zhang Y, Gao F, Han S, Cheah KS, Tse HF, et al. CRISPR/Cas9 genome-editing system in human stem cells: current status and future prospects. Mol Ther Nucleic Acids. 2017;9:230-41.

59. Grobarczyk B, Franco B, Hanon K, Malgrange B. Generation of isogenic human iPS cell line precisely corrected by genome editing using the CRISPR/Cas9 system. Stem Cell Rev Rep. 2015;11(5):774-87.

60. Miyaoka Y, Amanda H, Chan AH, Judge LM, Yoo J, Huang M, et al. Isolation of single-base genome-edited human iPS cells without antibiotic selection. Nat. Methods. 2014;11(3):291-3.

61. Huang $X$, Wang $Y$, Yan W, Smith C, Ye Z, Wang J, et al. Production of genecorrected adult beta globin protein in human erythrocytes differentiated from patient iPSCs after genome editing of the sickle point mutation. Stem Cells. 2015;33(5):1470-9.

62. Ovchinnikov DA, Withey SL, Leeson H, Lei UW, Sundarrajan A, Junday K, et al. Correction of ATM mutations in IPS cells from two ataxia-telangiectasia patients restores DNA damage and oxidative stress responses. Hum Mol Genet. 2020;29(6):990-1001.

63. Trionfini P, Ciampi O, Romano E, Benigni A, Tomasoni S. Generation of two isogenic knockout PKD2 iPS cell lines, IRFMNi003-A-1 and IRFMNi003-A-2, using CRISPR/Cas9 technology. Stem Cell Res. 2020. https://doi.org/10.1016/ j.scr.2019.101667.

64. Guo D, Liu H, Gao G, Liu Y, Zhuang Y, Yang F, et al. Creating a patient carried Men1 gene point mutation on wild type iPSCs locus mediated by CRISPR/Cas9 and ssODN. Stem Cell Res. 2017. https://doi.org/10.1016/j.scr. 2016.12.007.

65. Kawai K, Negoro R, Ichikawa M, Yamashita T, Deguchi S, Harada K, et al. Establishment of SLC15A1/PEPT1-knockout human-induced pluripotent 
stem cell line for intestinal drug absorption studies. Mol Ther Methods Clin Dev. 2019:17:49-57.

66. Nakamoto FK, Okamoto S, Mitsui J, Sone T, Ishikawa M, Yamamoto Y, et al. The pathogenesis linked to coenzyme Q10 insufficiency in iPSC-derived neurons from patients with multiple-system atrophy. Sci Rep. 2018;8(1): 14215.

67. Zhu W, Zhang B, Li M, Mo F, Mi T, Wu Y, et al. Precisely controlling endogenous protein dosage in hPSCs and derivatives to model FOXG1 syndrome. Nat Commun. 2019;10(1):928.

68. Xie F, Ye L, Chang JC, Beyer Al, Wang J, Muench MO, et al. Seamless gene correction of $\beta$-thalassemia mutations in patient-specific iPSCs using CRISPR/Cas9 and piggyBac. Genome Res. 2014;24(9):1526-33.

69. Song B, Fan Y, He W, Zhu D, Niu X, Wang D, et al. Improved hematopoietic differentiation efficiency of gene-corrected beta-thalassemia induced pluripotent stem cells by CRISPR/Cas9 system. Stem Cells Dev. 2015;24(9): 1053-65.

70. Jackówa J, Guoa Z, Hansena C, Abacia HE, Douceta YS, Shina JU, et al. CRISPR/Cas9-based targeted genome editing for correction of recessive dystrophic epidermolysis bullosa using iPS cells. Proc Natl Acad Sci U S A. 2019. https://doi.org/10.1073/pnas.1907081116.

71. Li HL, Fujimoto N, Sasakawa N, Shirai S, Ohkame T, Sakuma T, et al. Precise correction of the dystrophin gene in Duchenne muscular dystrophy patient induced pluripotent stem cells by TALEN and CRISPR-Cas9. Stem Cell Reports. 2015;4(1):143-54.

72. Dimmock DP, Zhang Q, Dionisi-Vici C, Carrozzo R, Shieh J, Tang LY, et al. Clinical and molecular features of mitochondrial DNA depletion due to mutations in deoxyguanosine kinase. Hum. Mutat. 2008;29:330-1.

73. Kondo T, Imamura K, Funayama M, Tsukita K, Miyake M, Ohta A, et al. iPSCbased compound screening and in vitro trials identify a synergistic antiamyloid b combination for Alzheimer's disease. Cell Reports. 2017;21:2304-12.

74. Teque F, Ye L, Xie F, Wang J, Morvan MG, Kan YW, et al. Genetically-edited iPSCs derived from HIV-1 infected patients on therapy can give rise to immune cells resistant to HIV-1 infection. AIDS. 2020. https://doi.org/10. 1097/QAD.0000000000002539.

75. Liao HK, Gu Y, Diaz A, Marlett J, Takahashi Y, Li M, et al. Use of the CRISPR/ Cas9 system as an intracellular defense against HIV-1 infection in human cells. Nat. Commun. 2015;6:6413.

76. Nguyen TM, Zhang Y, Pandolfi PP. Virus against virus: a potential treatment for 2019-nCov (SARS-CoV-2) and other RNA viruses. Cell Research. 2020:18990.

77. Blum R, Arumugam A, Wu J, Walcheck B, Kaufman D. Engineering human pluripotent stem cell-derived natural killer cells to prevent CD16a shedding for enhanced anti-tumor killing. Blood. 2016;128.

78. Ji J, Lee H, Argiropoulos B, Dorrani N, Mann J, Martinez-Agosto JA, GomezOspina N, et al. DYRK1A haploinsufficiency causes a new recognizable syndrome with microcephaly, intellectual disability, speech impairment, and distinct facies. Eur. J. Hum. Genet. 2015;23:1473-81.

79. Fernandes-Rosa FL, Daniil G, Orozco IJ, Göppner C, El Zein R, Jain V, et al. A gain-of-function mutation in the CLCN2 chloride channel gene causes primary aldosteronism. Nat. Genet. 2018;50:355-61.

80. Kumamoto T, Hanashima C. Evolutionary conservation and conversion of Foxg1 function in brain development. Dev Growth Differ. 2017;59(4):258-69.

81. Brunetti-Pierri N, Paciorkowski AR, Ciccone R, Della Mina E, Bonaglia MC, Borgatti $R$, et al. Duplications of FOXG1 in $14 q 12$ are associated with developmental epilepsy, mental retardation, and severe speech impairment. Eur. J. Hum. Genet. 2011;19:102-7.

82. Mitter D, Pringsheim M, Kaulisch M, Plümacher KS, Schröder S, Warthemann $\mathrm{R}$, et al. FOXG1 syndrome: genotype-phenotype association in 83 patients with FOXG1 variants. Genet Med. 2018;20(1):98-108.

83. De Filippis R, Pancrazi L, Bjørgo K, Rosseto A, Kleefstra T, Grillo E, et al. Expanding the phenotype associated with FOXG1 mutations and in vivo FoxG1 chromatin-binding dynamics. Clin. Genet. 2012;82:395-403.

84. Hovnanian A, Rochat A, Bodemer C, Petit E, Rivers CA, Prost C, et al. Characterization of 18 new mutations in COL7A1 in recessive dystrophic epidermolysis bullosa provides evidence for distinct molecular mechanisms underlying defective anchoring fibril formation. Am J Hum Genet. 1997; 61(3):599-610

85. Rousseau J, Chapdelaine P, Boisvert S, Almeida LP, Corbeil J, Montpetit A, et al. Endonucleases: tools to correct the dystrophin gene. J Gene Med. 2011;13(10):522-37.
86. Gee P, Lung MSY, Okuzaki Y, Sasakawa N, Iguchi T, Makita Y, et al. Extracellular nanovesicles for packaging of CRISPRCas9 protein and sgRNA to induce therapeutic exon skipping. Nature Communications. 2020. https:// doi.org/10.1038/s41467-020-14957-y.

87. Jing R, Corbett JL, Cai J, Beeson GC, Beeson CC, Chan SS, et al. A screen using iPSC-derived hepatocytes reveals NAD+ as a potential treatment for mtDNA depletion syndrome. Cell Rep. 2018;25(6):1469-84.

88. Spitalieri P, Quitadamo MC, Orlandi A, Guerra L, Giardina E, Casavola V, et al. Rescue of murine silica-induced lung injury and fibrosis by human embryonic stem cells. Eur Respir J. 2012. https://doi.org/10.1183/09031936. 00005511.

89. Nie J, Li Q, Wu J, Zhao C, Hao H, Liu H, et al. Establishment and validation of a pseudovirus neutralization assay for SARS-CoV-2. Emerg Microbes Infect. 2020;9(1):680-6.

90. Kleine-Weber H, Schroeder S, Krüger N, Prokscha A, Naim HY, Müller MA, et al. Polymorphisms in dipeptidyl peptidase 4 reduce host cell entry of Middle East respiratory syndrome coronavirus. Emerg Microbes Infect. 2020; 9(1):155-68.

91. Shalem O, Sanjana NE, Hartenian E, Shi X, Scott DA, Mikkelson T, et al. Genome-scale CRISPR-Cas9 knockout screening in human cells. Science. 2014;343(6166):84-7.

92. Tian X, Gu T, Patel S, Bode AM, Lee MH, Dong Z. CRISPR/Cas9 - an evolving biological tool kit for cancer biology and oncology. NPJ Precis Oncol. 2019. https://doi.org/10.1038/s41698-019-0080-7.

93. Khan FA, Pandupuspitasari NS, Chun-Jie H, Ao Z, Jamal M, Zohaib A, et al. CRISPR/Cas9 therapeutics: a cure for cancer and other genetic diseases. Oncotarget. 2016;7(32):52541-52.

\section{Publisher's Note}

Springer Nature remains neutral with regard to jurisdictional claims in published maps and institutional affiliations.
Ready to submit your research? Choose BMC and benefit from:

- fast, convenient online submission

- thorough peer review by experienced researchers in your field

- rapid publication on acceptance

- support for research data, including large and complex data types

- gold Open Access which fosters wider collaboration and increased citations

- maximum visibility for your research: over $100 \mathrm{M}$ website views per year

At BMC, research is always in progress.

Learn more biomedcentral.com/submissions 